\title{
New Concept for Dual-Layer Hydrophilic/Hydrophobic Composite Membrane for Membrane Distillation
}

\author{
Muhammad R. Bilad", Faisal A. Al Marzooqi ${ }^{\#}$ and Hassan A. Arafat
}

Institute Center for Water and Environment (iWater), Department of Chemical and Environmental Engineering, Masdar Institute of Science and Technology, PO Box 54224, Abu Dhabi, United Arab Emirates

\begin{abstract}
This study presents a new concept of a simple method for the synthesis of dual layer hydrophilic/hydrophobic composite membranes for membrane distillation (MD). The membranes were prepared of poly(vinylidenefluoride) (PVDF) by phase inversion. The synthesis was realized by allowing a full or partial penetration of the polymer solution through one or two non-woven support (NWS) layers. This was achieved by proper selection of a thin NWS having high stiffness, high porosity and low surface tension, in combination with a runny polymer solution and sufficient time gap between casting and coagulation. The applied preparation method was effective in yielding dual layer composite membranes. The first layer atop the NWS was a hydrophilic or slightly hydrophobic one (contact angle (CA) of $88-92^{\circ}$ ), while the bottom layer beneath the NWS was highly hydrophobic $\left(C A=132-140^{\circ}\right)$. The difference in surface energy between the top and bottom layers originated from a difference in morphology. A smooth and dense top layer is formed as a result of an instantaneous demixing, while a porous and multi-scale network with some degrees of spherulitical structure was formed on the bottom by a delayed demixing mechanism. Direct contact MD (DCMD) results showed that the obtained flux was comparable to other composite MD membranes with high salt rejection. Membrane alignment inside the MD module is a critical element in determining the membrane performance and is shown to significantly increase flux when a top facing feed configuration is used.
\end{abstract}

Keywords: Membrane distillation, poly(vinylidenefluoride), phase inversion, dual-layer, composite membrane.

\section{INTRODUCTION}

Membrane distillation (MD) is a non-isothermal separation process in which a hydrophobic membrane acts as an interface between the hot liquid (feed solution) and a colder permeate side. The hot water evaporates at the interface and the vapour (driven by the vapour pressure difference) is forced to cross to the other side of the membrane where it is collected as distillate. Despite its early introduction [1], large-scale application of MD is strongly limited by the lack of MD application-specific membranes that offers both high vapor flux and wetting resistance. Pore-wetting leads to both flux decay and poor salt deposition [2-4]. Membrane wetting occurs when the feed/permeate penetrates through the membrane pores or when vapor condenses in the pores. In addition, an MD module design that facilitates low temperature and concentration polarization is also essential [5]. Other MD membrane requirements such as low heat conductivity are also desirable.

In MD, the flux increases with an increase in membrane pore size and porosity, but decreases with an increase in membrane thickness and pore tortuosity.

\footnotetext{
*Address correspondence to this author at the Institute Center for Water and Environment (iWater), Department of Chemical and Environmental Engineering, Masdar Institute of Science and Technology, PO Box 54224, Abu Dhabi, United Arab Emirates; Tel: +(971)28109119; E-mail: harafat@masdar.ac.ae

"These authors contributed equally to this work.
}

A high MD flux can therefore be obtained using a thin high porosity membrane with high surface porosity and large pore size. On one hand, a membrane with a high water liquid entry pressure (LEP) is required to increase wetting resistance. High LEP is achieved by using a membrane with high hydrophobicity (i.e., high water contact angle, CA) and small maximum-pore size (or bubble point, BP). On the other hand, the heat conduction can be reduced by applying a thick and highly porous membrane. The latter is important since the conductive heat transfer coefficient of the gas entrapped within the membrane pore is an order of magnitude smaller than that of the solid membrane material. It is clear therefore that different requirements for high mass transfer and low heat transfer can lead to conflicting requirements vis-à-vis the desired membrane properties, especially thickness and pore size.

In order to enhance the MD performance, several membrane designs have been proposed in the literature based on the concept of single and multiplelayer membrane. Dual or multiple layer membranes, comprising of hydrophobic/hydrophilic layers, are attractive because they offers a shorter pathway of vapor transport [5-7]. Typically, in such membranes, the membrane is partially wetted during operation down into a certain distance within its thickness. Here, it is the hydrophilic layer that is wetted leaving a shorter pathway for vapor transport, only within the hydrophobic layer. The top hydrophobic thin layer is 
thus responsible for the mass transport, while the combination of both the hydrophobic layer and the wetted hydrophilic sub-layer contribute to conductive heat loss reduction and the overall mechanical integrity of the whole membrane [5].

There are several methods to make multiple-layer flat-sheet composite membranes, including grafting, plasma treatment, blending, etc. Grafting and plasma treatment were proven effective for cellulose acetate and cellulose nitrate membrane. They were modified via radiation graft polymerization of styrene and plasma polymerization of both vinyltrimethylsilicon/carbon tetrafluoride and octafluoro-cyclobutane, respectively [6-8]. Another approach is by adding fluorinated surface modifying macromolecules (SMM) into the casting solution [9-12]. During phase inversion, the SMM migrate to the membrane surface rendering it hydrophobic. While all these methods were effective in creating the targeted hydrophilic/phobic membrane, the radiation and plasma polymerization methods can alter the chemical structure of the membrane, while the use of SMM still requires optimization of the hydrophobic layer thickness and morphology. Recently, nano-fiber based triple layer hydrophilic/phobic membranes were also proposed to improve the MD membrane flux and wetting resistance [13]. In addition, a series of hydrophobic/hydrophilic hollow fiber membranes that offer promising flux (of up to ca. $84 \mathrm{~L} / \mathrm{m}^{2} \mathrm{~h}$ ) could be obtained by modifying the spinning parameters $[5,14]$.

In this study, to capitalize on the advantages of composite hydrophobic/hydrophilic membranes, a new concept is proposed using a novel and simple synthesis method, to prepare dual-layer composite flatsheet poly(vinylidenefluoride) (PVDF) membranes for MD application. In our method, we attempted to create a differential in the apparent hydrophobicity of the two membrane layers, by manipulating the morphology and microstructure of each layer, rather than invoking differences in the intrinsic hydrophobicity of the materials used. Thus, no changes in the chemical properties of the membrane were induced. PVDF was selected because it is a hydrophobic polymer that can be easily dissolved in common organic solvents and which has been vastly investigated as an MD membrane material via the phase inversion method [15]. Intrinsically, PVDF has a CA on the verge of hydrophobicity (CA: 80-95 ${ }^{\circ}$ [16] but PVDF membranes with very high apparent $C A$ can be created by controlling the membrane surface structure [17]. To form a flat-sheet membrane, a PVDF solution is typically cast on a glass plate or on an NWS and immersed in a non-solvent bath where phase inversion occurs. The proposed method in this study is based on the selection of NWS and casting parameter that allows full penetration of the polymer solution into the bottom of the NWS to form two layers: one above and the second below the NWS. The differences in solventnon-solvent exchange rate within the two sides yield two layers which have different microstructures leading to a difference in their hydrophobicity. The NWS was selected based on several criteria that ensure the formation of shrink- and defect-free membranes [18, 19].

\section{MATERIALS AND METHODS}

\subsection{Membrane Preparation}

All membrane samples were prepared via immersion precipitation. Thepolymer solution consisted of PVDF (Kynar 761, Arkema, molecular weight of $370,000 \mathrm{~g} / \mathrm{mol}$ ) dissolved at $15 \% \mathrm{w} / \mathrm{w}$ in dimethylacetamide (DMAC, Sigma-Aldrich). This choice of combination between the relatively molecular weight of the PVDF polymer grade used and the solution concentration is a result from many attempts (not shown) to obtain a polymer solution that is runny enough to penetrate the NWS but at the same time viscous enough to create a stable membrane layer on both sides of the NWS. The non-solvent was demineralized water (DI). Dual layer composite membranes were effectively prepared by a careful selection of the NWS type and casting conditions. Four different membranes were prepared in this work; (M1): the polymer solution was cast on a dry NWS that was placed on a flat metal plate, (M2): the polymer solution was cast on the first dry NWS which was placed atop a second dry NWS, all placed on a flat metal plate, (M3): like M2 but the second NWS was pre-wetted with DMAC, and (M4): like M2 but the second NWS was pre-wetted with ethanol, a weak non-solvent. The variations of the last three membrane types were aimed to improve the hydrophobicity as will be demonstrated later. The synthesis details are provided next.

For $\mathrm{M} 1$, after being thoroughly dissolved and degassed, the polymer solution was cast at $24^{\circ} \mathrm{C}$ using a doctor blade on the NWS (Novatexx 2481) to give a wet-casting thickness of $500 \mu \mathrm{m}$ (the final membrane thickness would be much lower than this due to evaporation and phase inversion). After casting, the polymer film was let idle in a chamber with a controlled relative humidity $(\mathrm{RH})$ of $60 \%$ for 5 min before it was 
immersed in a coagulation bath containing DI water. Several attempts to optimize the pre-coagulation humidity exposure time were carried out. The optimal time selected (5 $\mathrm{min}$ ) was that which was long enough to allow the polymer solution to penetrate the NWS, but at the same time short enough for polymer precipitation not to occur. Novatexx 2481 was specifically selected as the first NWS because it enabled a full gradual penetration of polymer solution into its bottom side due to its high porosity, high wettability with DMAC, low thickness and relatively high mechanical strength. After casting, the polymer film immediately percolated through the NWS to fill the voids in its structure, driven by gravity. This way, the formation of a dual layer membrane was possible: the first layer atop and the second beneath the NWS. Both layers were preserved via a fast phase inversion process during the immersion in water.

For membranes M2-M4, the synthesis protocol was similar to M1 except that, during casting, the first NWS (Novatexx 2481) was placed atop a second NWS (Novatexx 2473) where the polymer solution penetrated partially into the second NWS. Upon concluding the phase inversion process, the membrane was peeled off the second NWS. The peeling was done by separating the two NWS sheets by hand, leaving the first NWS embedded within the composite membrane. The objective of introducing a second NWS in M2-M4 is to induce multi-scale structure on the surface of the bottom layer, which resulted in additional macro-scale roughness. Such roughness is desired to increase the hydrophobicity, as reported elsewhere [20]. Here, the NWS plays three roles: creating roughness, facilitating the growth of polymer-rich phase during liquid-solid phase separation to form surface roughness, and restricting water intrusion to the nascent membrane from the bottom, thus delaying the precipitation process that leading to the generation of fibrils morphology. The objective of pre-wetting the second NWS is to prevent over-penetration of the polymer solution into the second NWS [21].

The details of preparation parameters for each sample are summarized in Table 1. The properties of the two NWS used (both donated by FreudenbergFilter, Germany) are provided in Table 2. An illustration of the membrane preparation process is shown in Figure 1.

\subsection{Membrane and NWS Characterization}

The microstructure of the membranes and the NWS was observed using scanning electron microscopy (SEM, Quanta-250, FEI). Samples were coated with gold and palladium at $50 \AA$ thickness prior to SEM analysis. The top and bottom layer thicknesses (top and bottom layer henceforth refer to the PVDF layers that form above the NWS and beneath it, respectively) were measured from the cross-section SEM images. Top surface SEM images were used to calculate

Table 1: Summary of Membrane Preparation Parameters. All Membranes Made from 15\% w/w PVDF)

\begin{tabular}{|c|c|c|c|}
\hline Membranes & First NWS & Second NWS & Treatment \\
\hline M1 & \multirow{4}{*}{ 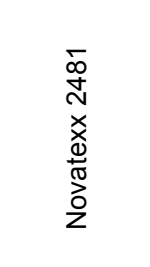 } & n.a. ${ }^{*}$ & Cast on a dry NWS (first NWS that was placed on a flat metal plate) \\
\hline M2 & & \multirow{3}{*}{ 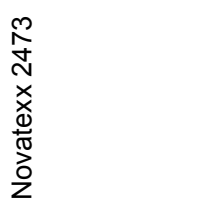 } & $\begin{array}{c}\text { Cast on the first NWS that was placed on the top of a dry second NWS } \\
\text { located on a flat metal plate }\end{array}$ \\
\hline M3 & & & Like (M2) but the second NWS was pre-wetted with a solvent \\
\hline M4 & & & $\begin{array}{l}\text { Like to (M2) but the second NWS was pre-wetted with ethanol (weak } \\
\text { non-solvent) }\end{array}$ \\
\hline
\end{tabular}

*n.a.: not applicable.

Table 2: Summary of NWS Properties

\begin{tabular}{|c|c|c|c|c|c|c|c|c|c|}
\hline \multirow[t]{2}{*}{ Novatexx } & \multirow[t]{2}{*}{ Material } & \multicolumn{2}{|c|}{ Thickness $(\mu \mathrm{m})$} & \multirow{2}{*}{$\begin{array}{c}\text { Porosity } \\
(\%)^{*}\end{array}$} & \multirow{2}{*}{$\begin{array}{l}\text { Density } \\
\left(\mathrm{g} / \mathrm{cm}^{3}\right)\end{array}$} & \multicolumn{2}{|c|}{ Area weight $\left(\mathrm{g} / \mathrm{m}^{2}\right)$} & \multirow{2}{*}{$\begin{array}{c}\text { Air Permeability } \\
\text { at } 200 \mathrm{~Pa} \\
\left(\mathrm{~L} / \mathrm{m}^{2} \mathrm{~s}\right)\end{array}$} & \multirow{2}{*}{$\begin{array}{c}\text { Contact } \\
\text { angle with DI } \\
\text { water }\left({ }^{\circ}\right)^{*}\end{array}$} \\
\hline & & $\begin{array}{l}\text { Supplier } \\
\text { data }\end{array}$ & Measured ${ }^{*}$ & & & Supplier data & Measured $^{*}$ & & \\
\hline 2481 & PET/PBT & 150 & $118.0 \pm 1.6$ & $44.2 \pm 0.6$ & 0.37 & 100 & $49 \pm 1$ & 120 & $0.0 \pm 0.0$ \\
\hline 2473 & PP/PE & 110 & $90.2 \pm 1.5$ & $64.7 \pm 11.9$ & 0.25 & 27 & $31 \pm 1$ & 2,100 & $113.7 \pm 2.3$ \\
\hline
\end{tabular}

PET: polyethylene terephthalate; PBT: polybutylene terephthalate; PP: polypropylene; PE: polyethylene. ${ }^{*}$ Values measured experimentally. 


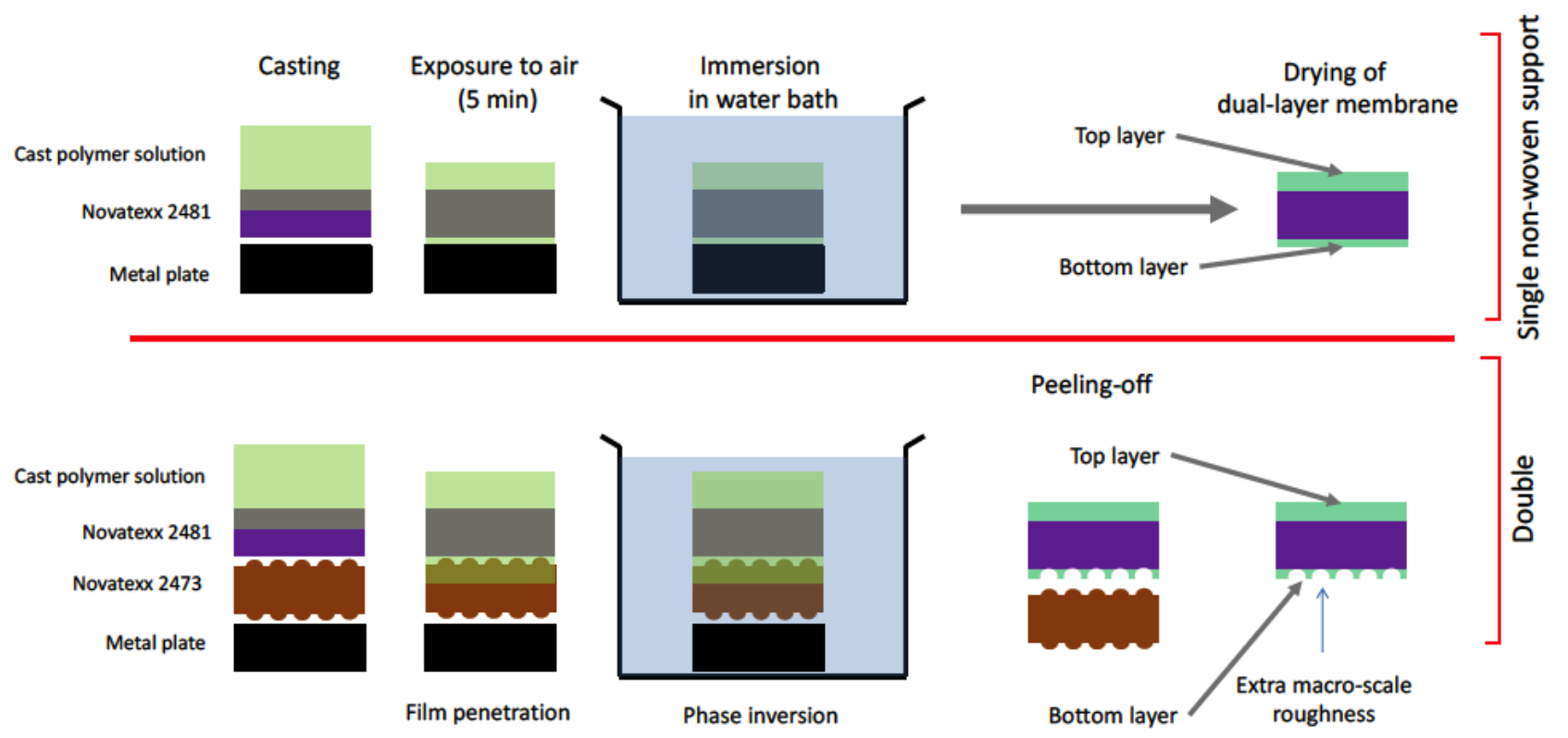

Figure 1: Illustration of different stages of membrane preparation process

surface porosity and surface pore density using an image analysis software (ImageJ, NIH). The NWS thickness and total membrane thickness were measured using a micrometer (Mitutoyo, Japan, accuracy of $\pm 1 \mu \mathrm{m})$. From these values, the net membrane thickness was calculated as the total thickness minus the thickness of the embedded NWS. The mean flow pore size (MPS), BP, pore size distribution (PSD) and Darcy's air permeability were measured using a capillary flow porometer (CFP, Porous Materials Inc., Ithaca, USA). Darcy's air permeability is measured by allowing air to axially pass through the membrane. The pressure drop and fluid flow is measured across the membrane and the software in the CFP machine uses Darcy's law to compute permeability. The CA of DI water on the membrane and NWS surface was measured using a goniometer (Krüss DSA $10 \mathrm{Mk} 2$ ) at $24^{\circ} \mathrm{C}$. Multiple measurements (at least 6 ) were taken at different locations of the same membrane sample to enhance data accuracy.

\subsection{DCMD Experiments}

DCMD experiments were performed in a custommade lab-scale setup. The setup consisted of feed and permeate tanks, respectively equipped with a heating and a cooling jacket to control their temperatures. The setup was fully instrumented with pressure, temperature, flow rate and conductivity sensors. More details of the MD setup can be found in [22]. The membrane coupons were rectangular $(4 \times 8.5 \mathrm{~cm})$. Plastic mesh-type spacers were used on both sides of the membrane to promote turbulence. The feed solution was $\sim 35 \mathrm{~g} / \mathrm{L} \mathrm{NaClin} \mathrm{DI}$ water corresponding to a conductivity of $46-50 \mathrm{mS} / \mathrm{cm}$. The liquid in permeateside was DI water. All DCMD experiments were carried out using a flow rate of $20.8 \mathrm{~L} / \mathrm{h}$ on both the feed and permeate sides (corresponding to a linear flow velocity of $0.08 \mathrm{~m} / \mathrm{s}$ ). During each experiment ( 3 hours), the average feed and permeate temperatures were $68 \pm 2^{\circ} \mathrm{C}$ and $29 \pm 2^{\circ} \mathrm{C}$, respectively. Permeate overflow was continuously measured using a microbalance and the membrane flux was calculated from this value. The salt rejection (SR) factor was calculated as follow:

$S R(\%)=\left(1-\frac{C_{\text {premeate }}}{C_{\text {Feed }}}\right) \cdot 100 \%$

Where $\mathrm{C}_{\text {Feed }}$ and $\mathrm{C}_{\text {Permeate }}$ are the salt concentrations in the feed and permeate streams (in $\mathrm{g} / \mathrm{L})$, respectively.

Both top and bottom surfaces of the four membranes can act as a separation layer for the DCMD process. Thus, DCMD experiments were performed with two membrane configuration: (1) top layer facing the feed side (TFF) and (2) top layer facing the permeate side (TFP). In the TFF configuration, since the top layer is hydrophilic (as will be shown later), the liquid-vapor interface separation occurs inside the membrane by allowing penetration of liquid feed to a certain depth of the membrane. In the TFP configuration, liquid intrusion is prevented due to the highly hydrophobic nature of the bottom surface (discussed later). Both TFF and TFP were performed 
using similar membrane coupons and were conducted by simply reversing the membrane orientation.

\section{RESULTS AND DISCUSSION}

\subsection{Membrane Characteristics}

The four different synthesis protocols applied in this study had a clear effect on membrane properties (Table 3). The top layer of all membranes is thicker than the bottom layer, ascribed to the restriction on polymer solution penetration. The top and bottom layers have significantly different surface energies (CA values) and structures (Figures 2 and 3 ). The contrast between the surface properties of the two layers is desired in this study. The CA of the top layer indicates a surface that is slightly hydrophilic to slightly hydrophobic (CA of 88.1-92.2 ${ }^{\circ}$ ), while the bottom layer is highly hydrophobic (CA of $132.5-140.1^{\circ}$ ). The differences in surface properties of the two layers is attributed to two different membrane formation mechanisms. For the top layer, during the precipitation process (immersion in water), the polymer molecules at the top of the cast film are always subjected to a force that tends to bring them down into the solvent interior because of the surface- and interfacial-tension forces of the polymer-air and polymer-water systems, respectively [23]. Since the polymer molecules cannot migrate downward easily from the interface, the polymer chains are flattened under the influence of the above forces. A smooth and flat surface morphology is then formed, which led to the low CA of the top surface. This corresponds to an LEP value of $0-22.2 \mathrm{kPa}$, as predicted by the Young-Laplace equation. Smooth surface allows limited air entrapment in the surface trough. Thus, it is featured by a relatively high surface energy that lowers its CA. The CA values of the top membrane surface in this study are still within the range for PVDF membranes prepared using the immersion precipitation technique employing water as a non-solvent that produce a membrane with a smooth surface $[18,19,24,25]$.

The high contact angle values on the bottom layer surface $\left(132-140^{\circ}\right)$ are attributed to the high roughness. Rough structure is a result of the porous multi-scale network with some degrees of spherulitical structure in the membrane matrix (Figure 3). This kind of surface structure was also reported elsewhere when employing a coagulation medium containing weak

Table 3: Summary of Membrane Properties

\begin{tabular}{|c|c|c|c|c|}
\hline Membranes/Properties & M1 & M2 & M3 & M4 \\
\hline \multicolumn{5}{|l|}{ Thickness $(\mu \mathrm{m})$} \\
\hline Top (SEM) & 71 & 90 & 124 & 138 \\
\hline Bottom (SEM) & 44 & 39 & 54 & 70 \\
\hline Net-membrane (SEM) & 115 & 129 & 178 & 208 \\
\hline Total (Net-membrane + NWS) $($ SEM) & $228.7 \pm 11.5$ & $190.6 \pm 5.0$ & $296.5 \pm 5.2$ & $303.0 \pm 7.7$ \\
\hline Net membrane (micrometer) & 110.7 & 72.6 & 178.5 & 185 \\
\hline Porosity (\%) & $70.6 \pm 3.8$ & $72.1 \pm 2.0$ & $79.8 \pm 1.5$ & $81.6 \pm 2.3$ \\
\hline \multicolumn{5}{|l|}{ Contact angle $\left({ }^{\circ}\right)$} \\
\hline Top & $89.8 \pm 0.7$ & $88.1 \pm 1.1$ & $91.6 \pm 1.9$ & $92.2 \pm 4.2$ \\
\hline Bottom & $133.7 \pm 2.8$ & $135.2 \pm 5.8$ & $132.5 \pm 2.9$ & $140.1 \pm 2.8$ \\
\hline \multicolumn{5}{|l|}{ Pore size $(\mu \mathrm{m})$} \\
\hline Mean flow & 0.095 & 0.1079 & 0.0816 & 0.0672 \\
\hline Bubble point & 0.264 & 0.3133 & 0.3144 & 0.2536 \\
\hline \multicolumn{5}{|l|}{ Liquid entry pressure $(\mathrm{kPa})^{*}$} \\
\hline Top & $N / A^{* *}$ & $N / A^{* *}$ & 13.1 & 22.2 \\
\hline Bottom & 376.9 & 326.1 & 309.4 & 435.7 \\
\hline Surface porosity (\%) & 12.97 & 7.04 & 11.85 & 11.92 \\
\hline Surface pore density (pore/100 um²) & 6746 & 8033 & 5207 & 6871 \\
\hline
\end{tabular}

${ }^{*}$ calculated using Young-Laplace equation [24].

${ }^{* *} \mathrm{CA}<90^{\circ}$. 

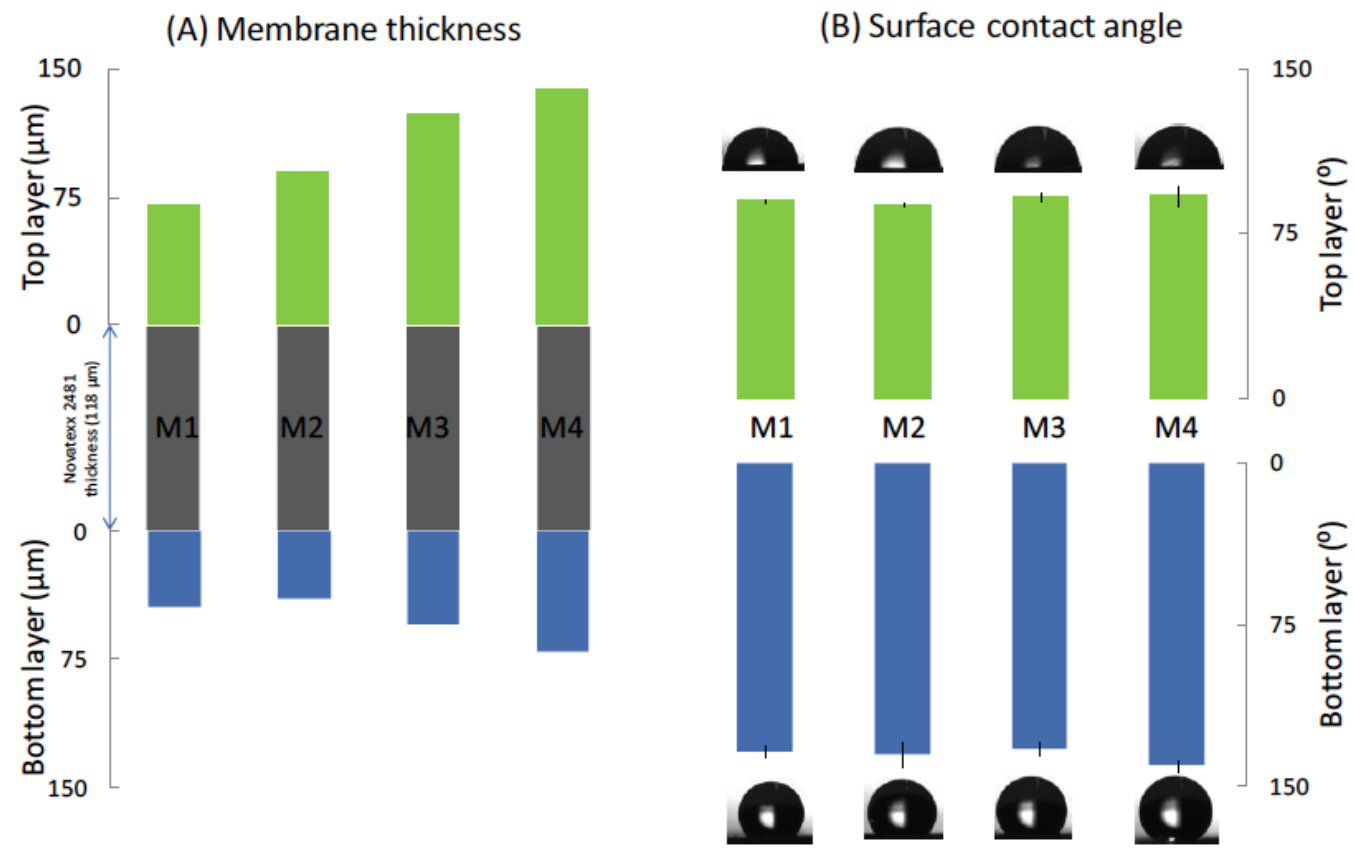

Figure 2: Membrane thickness and surface contact angle (CA). The preparation configurations affect both top and bottom membrane thickness. Pre-wetting of second NWS with ethanol slightly increase the bottom surface CA $\left(140.1^{\circ}\right.$ compared to the rests of $\left.132.5-135.2^{\circ}\right)$.

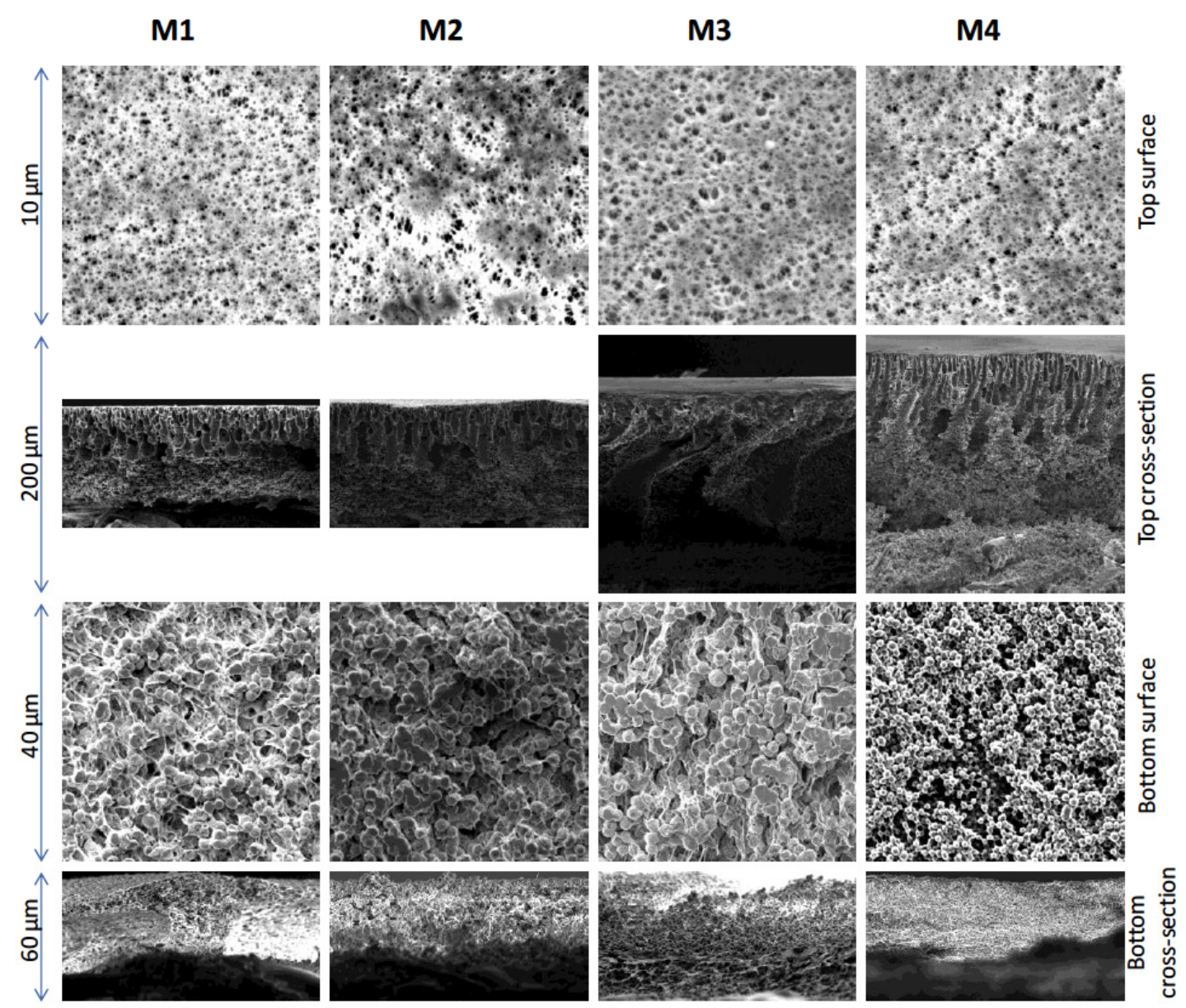

Figure 3: SEM images of membrane samples showing a smooth surface structure of the top layer and three-dimensional structure with some degrees of spherulitical structure at the bottom surface. 
non-solvent [5]. In our case, delayed demixing is facilitated by a slow transport of both DMAC and water into and out of the bottom layer. The transport is hindered by the solidifying polymer on the top layer, while no transport occurs through the bottom side (bordered by a metal plate). The effective use of delayed demixing phenomenon was also employed elsewhere to impose surface roughness on a single layer membrane [17].

While the morphology of the top surfaces of all membranes are similar, the bottom surface of M4 is significantly different from the other bottom surfaces (Figure 3). The size of the spherulites at the bottom layer of M4 is much smaller than the rest. This can be attributed to the use of ethanol to pre-wet the second NWS. Ethanol is considered as a weak non-solvent for PVDF. Thus, it promotes phase separation immediately when in contact with the polymer solution. The use of weaker non-solvent for the formation of surface roughness has also been demonstrated in earlier studies [5, 17]. Application of weak non-solvent leads to small liquid-liquid miscibility gap of the PVDF-DMACethanol system which favors a delayed de-mixing. On the other hand, a system with strong non-solvent (e.g., PVDF-DMAC-water) experiences an instantaneous de- mixing via the nucleation and growth mechanism, resulting in a smooth, flat and dense surface [26]. The unique structure of M4 granted it a higher CA of its bottom surface than the rest (Figure 2). In fact, it seems that the impact of these micro-scale structural features was more pronounced than the impact of macro-scale roughness induced by the imprints of the second NWS on the bottom layer.

The cross section SEM images show that all four membranes had an asymmetric structure at the top layer and a symmetric structure at the bottom layer (Figure 3). This structure is a result of two different formation mechanisms. The top layer experiences an instantaneous de-mixing, while the bottom experiences a delayed de-mixing, as discussed earlier. The top layer structure of M1-M3 is dense, supported by a finger- or sponge-like structure underneath it. On the other hand, the top layer of M4 has a dense structure supported by finger-like and granular structures.

Another implication of the liquid choice for prewetting the second NWS is a higher total thickness of M4 compared to M3. Since ethanol is a non-solvent for the PVDF/DMAC system, phase separation immediately started once the polymer solution was in
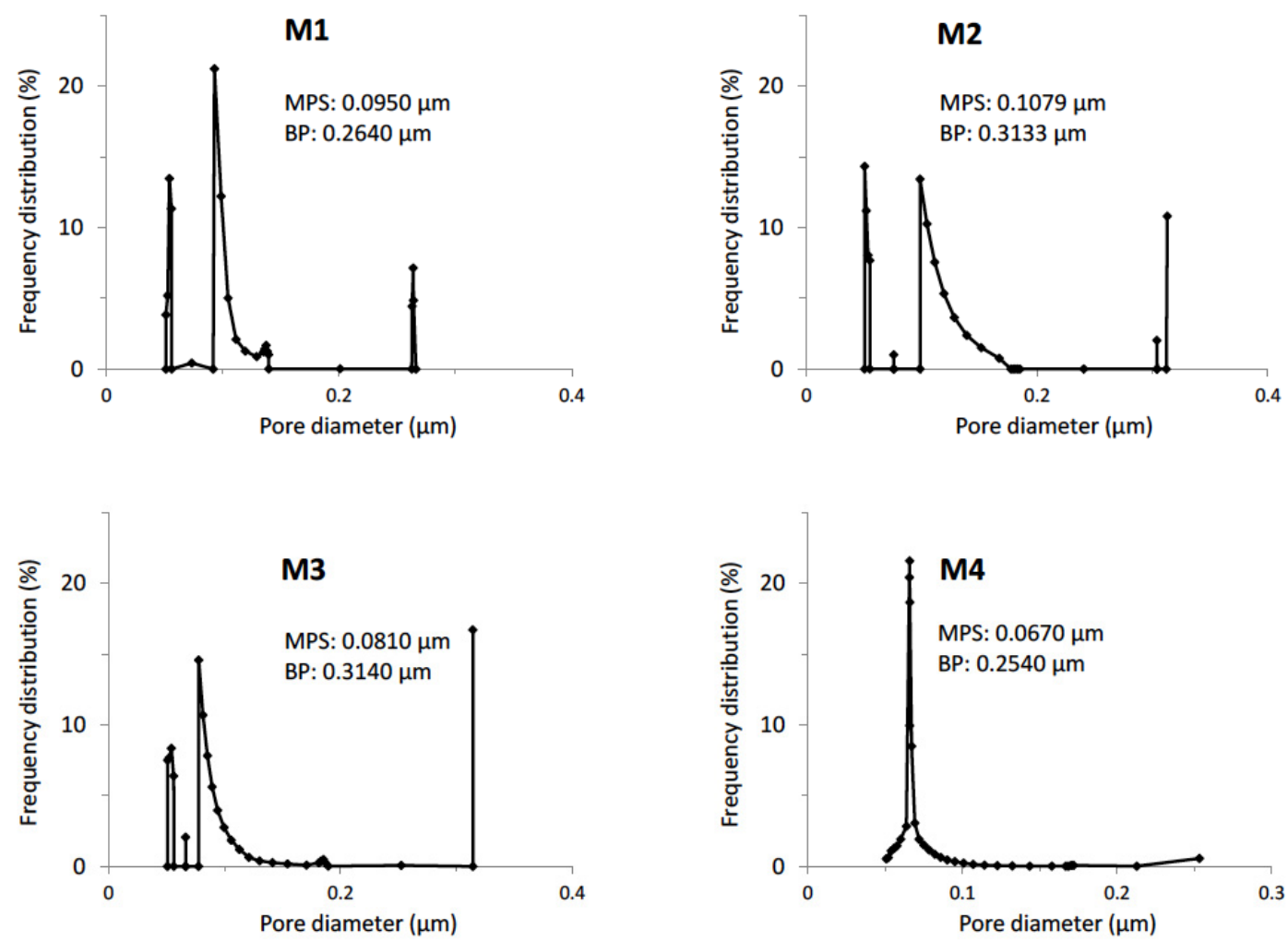

Figure 4: Pore size distributions (PSD) of membrane samples and their histogram. Line charts show distribution of each detected pore, while the bar charts show pore size ranges histograms. A distinct difference of PSD exists between M1-3 and M4, in which the latter is Gaussian and the formers are tri-modal. MPS is mean flow pore size and BP is bubble point pore size. 
contact with the second NWS. This increased the polymer solution viscosity and thus limited further penetration thereof into the second NWS. For M3, on the other hand, since DMAC is a strong solvent of PVDF, dissolution of PVDF into the bulk of the wetting liquid can be expected.

The PSD of M1-M3 is tri-modal, while the PSD of M4 is Gaussian, with a very sharp modal (Figure 4). The tri-modal distribution in M1-M3 originates from the nature of the membrane formation mechanism which includes nucleation and growth mechanism. The results suggest that in addition to improving the hydrophobicity of the bottom membrane layer, the introduction of ethanol as a wetting liquid for M4 significantly alters the membrane PSD. To a smaller degree, it also increases the membrane porosity from $71-80 \%$ for M1-M3 and up to $82 \%$ for M4. However, despite boosting a sharp PSD, M4 has a substantially lower MPS of $0.0672 \mu \mathrm{m}$, compared to the other membranes $(0.0816-0.1079 \mu \mathrm{m})$.

All membranes have considerably low BP (less than $0.32 \mu \mathrm{m})$, which is below the recommended upper bound of $0.5 \mu \mathrm{m}$ for MD applications [27]. This small $\mathrm{BP}$, compounded with a high $\mathrm{CA}$, contributed to a high LEP value for wetting from the bottom side (LEP of 309.4-435.7 kPa, as calculated by the Young-Laplace equation). On the other hand, the LEP value for wetting from the top side was low (LEP of up to $22.2 \mathrm{kPa}$, as calculated by the Young-Laplace equation), a direct result of its low CA.

\subsection{DCMD Performance}

DCMD tests were conducted in two modes; top layer facing the feed side (TFF) and top layer facing the permeate side (TFP). It was clearly noticed that both membrane configuration and membrane type significantly affect both DCMD flux and SR, as seen in Table 4. The TFF configuration yielded a much higher flux $\left(16-21 \mathrm{~L} / \mathrm{m}^{2} \mathrm{~h}\right)$ and SR $(99.5-99.8 \%)$ compared to the TFP configuration (flux of $7.2-10.4 \mathrm{~L} / \mathrm{m}^{2} \mathrm{~h}$ and SR of 95.7-99.6\%). The fluxes obtained for both configurations are within the general range of other PVDF composite membranes reported in literature [15, $22,25,28]$. It is worth noting that while our flux values for the TFF configuration are above the average range reported for most MD membranes, they are not as high as some of the values reported for composite hydrophilic/phobic membranes, generally ranging from 14-83 L/m².h $[5,14,29]$.

The second observation was that the fluxes of all tested membranes in the TFF mode were stable over the test duration (200 $\mathrm{min}$ ) (Figure 5). On the other hand, a slow decline of flux was observed for the TFP configuration. The SR of some membranes tested in TFP configuration also showed a slow decline, which reduced their prospect for long-term DCMD operation. The large difference in performance between the TFF and TFP configurations is very interesting because by merely reversing the membrane orientation, the flux can be improved significantly (in some case by more than $200 \%$ ). To understand the interplay of the two membrane layers, flux and salt rejection, we propose two theories: stagnant liquid bridging and reduction of effective membrane area.

Stagnant liquid bridging occurs because of partial membrane wetting. When facing the permeate in the TFP configuration, the hydrophilic top layer was wet due to its hydrophilic nature. This was augmented by

Table 4: Summary of Flux, Salt Rejection and Trans-Membrane Pressure Obtained at the End of DCMD Tests. Test Parameters: Feed temp. $=68 \pm 2^{\circ} \mathrm{C}$, Permeate temp. $=29 \pm 2^{\circ}\left(\Delta \mathrm{T}: 3^{\circ}\right)$, Feed Flow Rate $=$ Permeate Flow Rate $=20.8$ L/h

\begin{tabular}{|c|c|c|c|c|}
\hline Membrane & Membrane orientation & Flux $\left(L / m^{2} h\right)$ & Salt rejection (\%) & TMP (kPa) \\
\hline M1 & \multirow{4}{*}{ TFF } & $16.0 \pm 0.4$ & $99.8 \pm 0.2$ & -2.1 \\
\hline M2 & & $17.1 \pm 0.9$ & $99.7 \pm 0.2$ & -2.0 \\
\hline M3 & & $16.6 \pm 0.9$ & $99.7 \pm 0.2$ & -1.6 \\
\hline M4 & & $21.1 \pm 0.3$ & $99.5 \pm 0.0$ & -0.5 \\
\hline M1 & \multirow{4}{*}{ TFP } & $10.4 \pm 0.5$ & $99.6 \pm 0.3$ & -2.1 \\
\hline M2 & & $7.2 \pm 0.8$ & $98.8 \pm 0.8$ & -2.2 \\
\hline M3 & & $9.7 \pm 1.4$ & $95.7 \pm 1.2$ & -1.7 \\
\hline M4 & & $7.1 \pm 0.8$ & $99.5 \pm 0.2$ & 0.0 \\
\hline
\end{tabular}

TFF: top lacer facing the feed side; TFP: top layer facing the permeate side. TMP is trans-membrane pressure, defined as $\mathrm{P}_{\mathrm{Feed}}-\mathrm{P}_{\text {permeate }}$ 


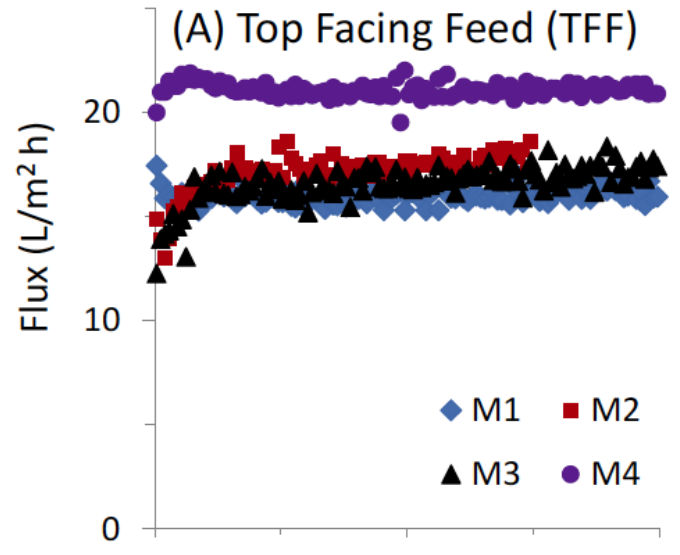
(B) Top Facing Permeate (TFP)
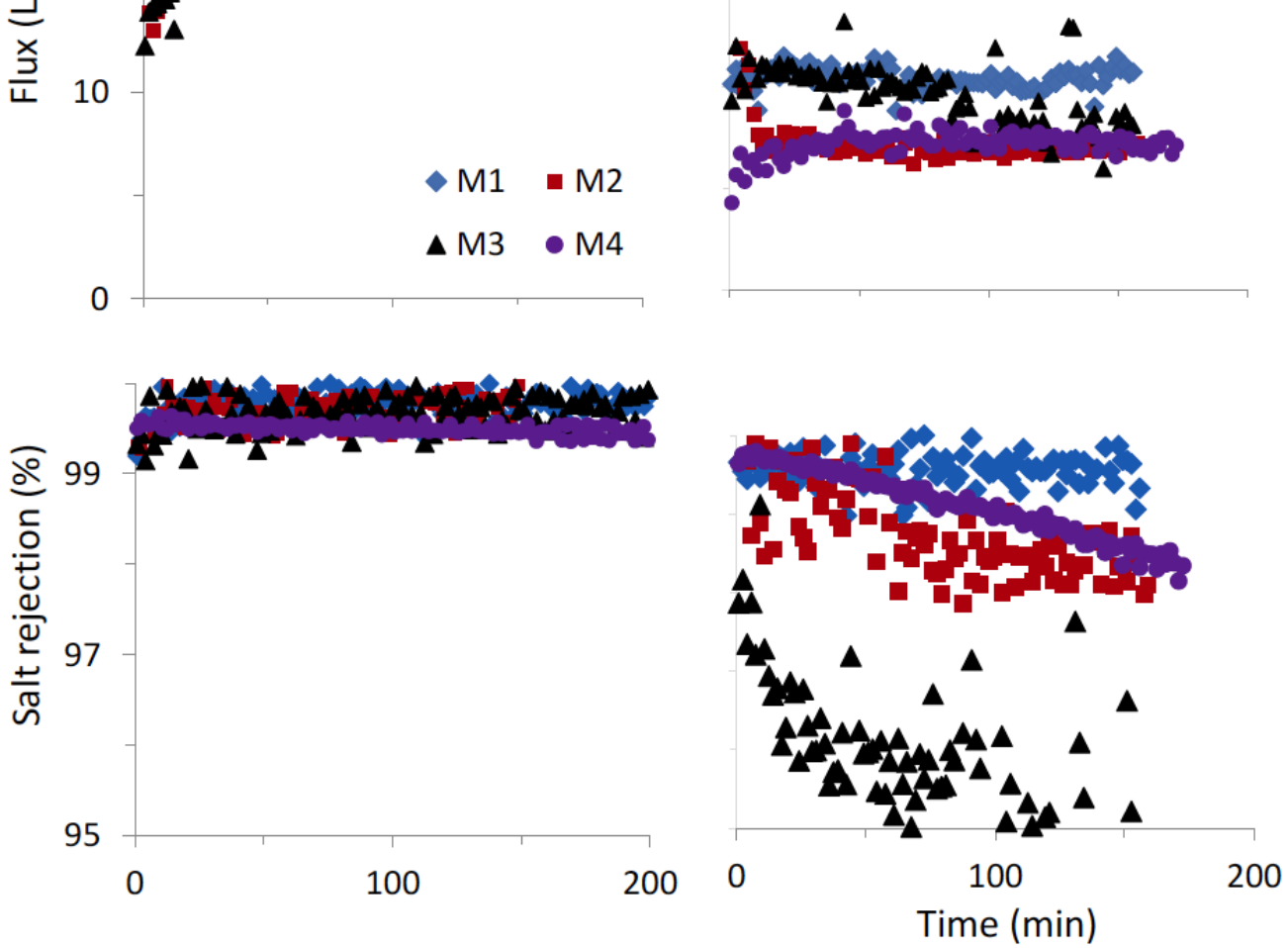

Figure 5: Evolution of DCMD flux and salt rejection showing the advantage of having hydrophilic layer facing the feed side to improve flux and rejection and prevent membrane wetting.

the slightly higher liquid pressure on the permeate side (see TMP values in Table 4). The occurrence of higher liquid pressure on the permeate side in this study was not intended. The flow rates of both hot and cold streams were set equal $(20.8 \mathrm{~L} / \mathrm{h})$, but the pressure drop was slightly higher on the feed side because of the larger number of sensors installed in that side. Overtime, the extent of pore wetting increased which ultimately led to liquid bridging across the full membrane thickness. This bridging potentially caused (1) a reduction of available free pores for vapor transport which lowered the flux, (2) a diffusive transport of salts from the feed to permeate side, driven by concentration gradient, reducing $S R$, and (3) a reverse convective flow of permeate to the feed side, driven by TMP, which lowers the net flux. The latter effect may be the least likely of all three. Building on the same logic, for the TFF configuration, the membranes were also wetted from the feed side (now the hydrophilic side) but the extent of full liquid-bridging was limited by the highly hydrophobic nature of the bottom layer, which faced a higher hydrostatic pressure on the permeate side. Hence, two distinctly different pathways of water intrusion could be expected in the two configurations. For the TFP, the intruding water passed a hydrophilic layer moving towards a hydrophobic layer but with no distinct cut-off in surface energy across the thickness (smooth transition of surface energy), while in the TFF configuration, a high $\mathrm{CA}$ of the membrane surface acted as a hindrance preventing liquid penetration.

The second theory which could explain the observed flux and SR trends is the reduction in available effective membrane area. This reduction of effective membrane area is proposed due to the highly rough morphology of the bottom layer. Multi-scale morphology coupled with highly rough surface promote the entrapment of air pockets on the bottom membrane surface, thus reducing the available surface area for heat and mass transfer. Therefore, when operating in TFP mode, less effective membrane area was available for vapour transport.

The distinctly higher flux observed for M4 in the TFF mode (Table 4) is worth elucidation. The first attempts 

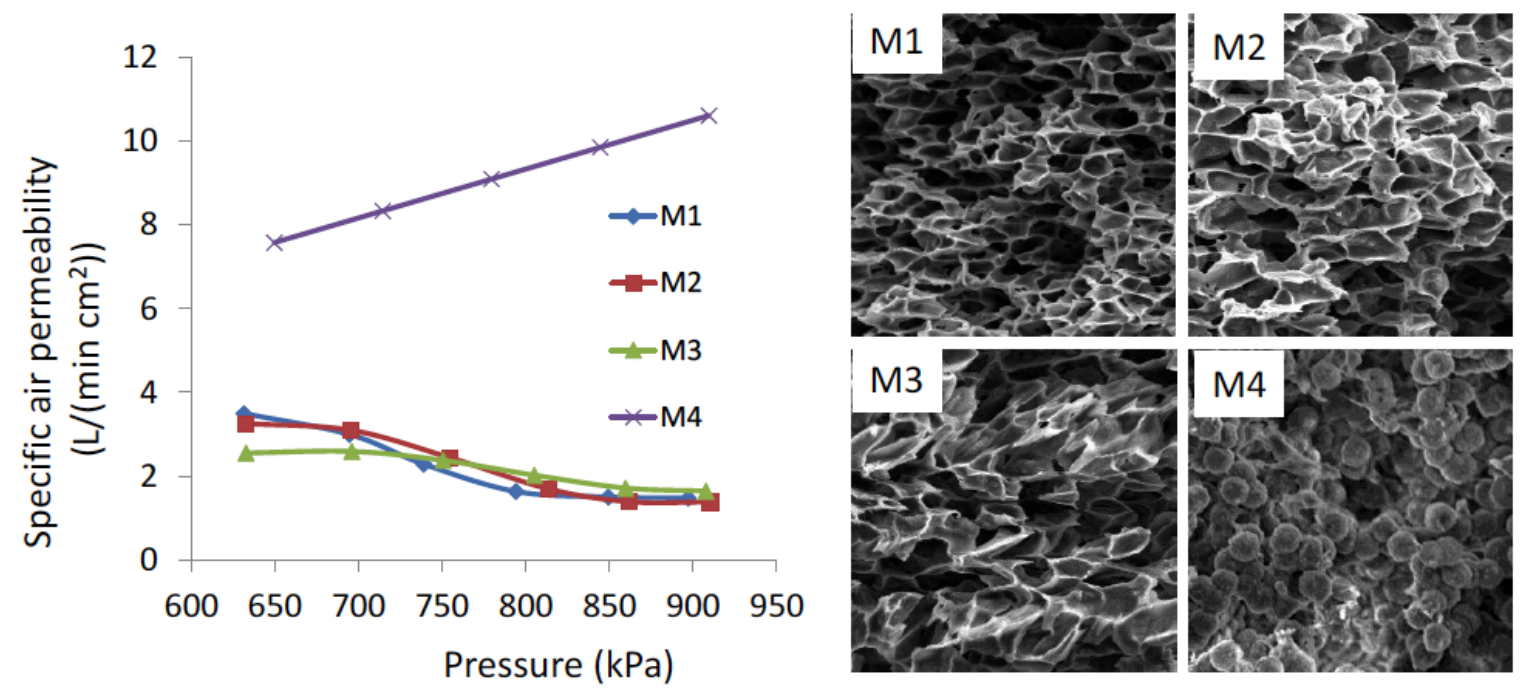

Figure 6: Darcy's air permeability of membranes M1-M4 showing a significantly higher specific permeability of M4. Also shown are the cross section SEM images of the structure of the PVDF formed within the NWS zone in the membranes showing a unique lumpy (grainy) morphology of M4 as opposed to M1-M3.

to understand this higher flux of $\mathrm{M} \$$ based on the individual membrane properties in Table 3, including thickness, MPS, PSD, porosity and CA led to inconclusive conclusions. For instance, M4 is the most porous, but it is also the thickest and the smallest in MPS. Nonetheless, the observed high flux of M4 can be explained based on its higher Darcy's air permeability (Figure 6). This higher permeability is attributed to M4'soverall structure. For instance, the effective thickness and the effective porosity are largely reduced based on the proposed stagnant liquid bridging theory during DCMD operation since the macro-voids underneath the hydrophilic top layer are most likely wet. The extent of wetting is also affected by the structure of the PVDF formed within the NWS zone as shown in Figure 6. A distinct difference in structure is shown for M4 compared to the rest (M1-M3 looked very similar).

To summarize, the occurrence of controlled partial membrane wetting in a dual-layer hydrophilic/ hydrophobic membrane was originally sought to shorten the vapour transport pathway and thus increase the flux. A modest increase of flux above the average of many reported values was achieved. However, by considering the nature of partial membrane wetting in the TFF configuration, according to the proposed liquid bridging theory, the advantage offered by a controlled partial wetting may be shortlived. This calls for further membrane optimization via a number of pathways. For one, the liquid bridging phenomenon in TFP configuration can probably be eliminated by using a membrane with a clearer cut-off between its hydrophobic and hydrophilic layer. Such cut-off can be induced by more dramatic structural differences, which may be achieved via the selection of wetting liquid of the second NWS for example. Alternatively, optimizing the thickness of the top and bottom layers of the membrane, by controlling the percolation of the PVDF solution into the NWS, can offer a better control of partial membrane wetting. Development of optimization strategies for such membranes will be a subject of a future study.

\section{CONCLUSIONS}

Dual layer hydrophilic-hydrophobic flat-sheet composite PVDF membranes was prepared using a simple membrane casting process involving a proper selection of NWS material and casting parameters without changing the polymer chemistry. This was achieved by applying a NWS that has high stiffness and porosity but low surface tension and thickness, in combination with a runny polymer solution. This set of parameters enabled a full penetration of the polymer solution underneath the NWS to form a dual layer membrane, with the first layer being more hydrophiliclocated at the top of the NWS and the second layer, being more hydrophobic, at the bottom of the NWS. The difference in surface energy of the top and bottom layers is ascribed to their structure that originated from two distinct membrane formation mechanisms. A smooth and dense top layer was formed as a result of an instantaneous de-mixing, while a porous and multi-scale network with some degrees of spherulitical structure was formed at the bottom as a 
result of a delayed de-mixing. The latter effect is more pronounced when the second NWS is pre-wetted with ethanol, a weak non-solvent for PVDF/DMAC. Prewetting with ethanol also altered the cross-section of the structure of the PVDF formed within the NWS zone of the membranes from sponge-like (M1-M3) to a grainy structure and also changed the membrane PSD from tri-modal (M1-M3) to Gaussian (M4). DCMD results showed that the obtained flux range using these dual layer membranes was comparable to other composite MD membranes. However, membrane layout (configuration) within the MD module (hydrophilic layer facing feed or permeate side) has proven to be a very important factor influencing the flux, SR, and the robustness of the latter. ATFF configuration offered substantial flux enhancement as opposed to TFP, which was explained based on liquid bridging and effective membrane surface area reduction. M4 showed a much better DCMD flux compared to the rest thanks to its overall structure.

\section{ACKNOWLEDGEMENT}

This work was funded by the Cooperative Agreement between the Masdar Institute of Science and Technology, Abu Dhabi, UAE and the Massachusetts Institute of Technology (MIT), Cambridge, MA, USA, Reference No. 02/MI/MI/ CP/11/07633/GEN/G/00.

\section{REFERENCES}

[1] Bodell BR. Distillation of saline water using silicone rubber membrane. US3361645 A, 02-Jan-1968.

[2] El-Bourawi MS, Ding Z, Ma R, Khayet M. A framework for better understanding membrane distillation separation process. J Membr Sci 2006; 285(1-2): 4-29.

http://dx.doi.org/10.1016/j.memsci.2006.08.002

[3] Lawson KW, Lloyd DR. Membrane distillation. J Membr Sci 1997; 124(1): 1-25.

http://dx.doi.org/10.1016/S0376-7388(96)00236-0

[4] Warsinger DM, Swaminathan J, Guillen-Burrieza E, Arafat $\mathrm{HA}$, Lienhard VJH. Scaling and fouling in membrane distillation for desalination applications: A review. State---Art Rev Desalination 2015; 356: 294-313.

http://dx.doi.org/10.1016/j.desal.2014.06.031

[5] Bonyadi S, Chung TS. Flux enhancement in membrane distillation by fabrication of dual layer hydrophilichydrophobic hollow fiber membranes. J Membr Sci 2007; 306(1-2): 134-146. http://dx.doi.org/10.1016/.j.memsci.2007.08.034

[6] Cheng DY, Wiersma SJ. Composite membrane for a membrane distillation system. US4419242 A, 06-Dec-1983.

[7] Wu Y, Kong Y, Lin X, Liu W, Xu J. Surface-modified hydrophilic membranes in membrane distillation. J Membr Sci 1992; 72(2): 189-196. http://dx.doi.org/10.1016/0376-7388(92)80199-T

[8] Kong Y, Lin X, Wu Y, Chen J, Xu J. Plasma polymerization of octafluorocyclobutane and hydrophobic microporous composite membranes for membrane distillation. J Appl Polym Sci 1992; 46(2): 191-199.

\section{http://dx.doi.org/10.1002/app.1992.070460201}

[9] Khayet M, Matsuura T. Application of surface modifying macromolecules for the preparation of membranes for membrane distillation. Desalination 2003; 158(1-3): 51-56. http://dx.doi.org/10.1016/S0011-9164(03)00432-6

[10] Qtaishat M, Khayet M, Matsuura T. Novel porous composite hydrophobic/hydrophilic polysulfone membranes for desalination by direct contact membrane distillation. J Membr Sci 2009; 341(1-2): 139-148.

http://dx.doi.org/10.1016/j.memsci.2009.05.053

[11] Qtaishat M, Rana D, Khayet M, Matsuura T. Preparation and characterization of novel hydrophobic/hydrophilic polyetherimide composite membranes for desalination by direct contact membrane distillation. J Membr Sci 2009; 327(1-2): 264-273. http://dx.doi.org/10.1016/j.memsci.2008.11.040

[12] Khayet M, Mengual JI, Matsuura T. Porous hydrophobic/hydrophilic composite membranes: Application in desalination using direct contact membrane distillation. $J$ Membr Sci 2005; 252(1-2): 101-113. http://dx.doi.org/10.1016/j.memsci.2004.11.022

[13] Prince JA, Rana $D$, Matsuura $T$, Ayyanar $N$, Shanmugasundaram TS, Singh G. Nanofiber based triple layer hydro-philic/-phobic membrane - a solution for pore wetting in membrane distillation. Sci Rep 2014; 4. http://dx.doi.org/10.1038/srep06949

[14] Edwie F, Teoh MM, Chung T-S. Effects of additives on duallayer hydrophobic-hydrophilic PVDF hollow fiber membranes for membrane distillation and continuous performance. Chem Eng Sci 2012; 68(1): 567-578.

http://dx.doi.org/10.1016/j.ces.2011.10.024

[15] Kang G, Cao Y. Application and modification of poly(vinylidene fluoride) (PVDF) membranes - A review. J Membr Sci 2014; 463: 145-165

http://dx.doi.org/10.1016/j.memsci.2014.03.055

[16] Zhao Y-H, Qian Y-L, Zhu B-K, Xu Y-Y. Modification of porous poly (vinylidene fluoride) membrane using amphiphilic polymers with different structures in phase inversion process. J Membr Sci 2008; 310(1): 567-576. http://dx.doi.org/10.1016/j.memsci.2007.11.040

[17] Peng M, Li H, Wu L, Zheng Q, Chen Y, Gu W. Porous poly(vinylidene fluoride) membrane with highly hydrophobic surface. J Appl Polym Sci 2005; 98(3): 1358-1363. http://dx.doi.org/10.1002/app.22303

[18] Huo R, Gu Z, Zuo K, Zhao G. Preparation and properties of PVDF-fabric composite membrane for membrane distillation. Desalination 2009; 249(3): 910-913. http://dx.doi.org/10.1016/..desal.2009.06.069

[19] Yang Y, Rana D, Matsuura T, Zheng S, Lan CQ. Criteria for the selection of a support material to fabricate coated membranes for a life support device. RSC Adv 2014; 4(73): 38711-38717.

\section{http://dx.doi.org/10.1039/C4RA04638B}

[20] Tao M, Xue L, Liu F, Jiang L. An Intelligent Superwetting PVDF Membrane Showing Switchable Transport Performance for Oil/Water Separation. Adv Mater 2014 26(18): 2943-2948 http://dx.doi.org/10.1002/adma.201305112

[21] Bottino A, Capannelli G, Comite A, Oliveri M. Development of novel membranes with controlled porosity from fluorinated polymer. Flltration 2004; 4(2): 130-135.

[22] Zhenxin Z, Matsuura T. Discussions on the formation mechanism of surface pores in reverse osmosis, ultrafiltration, and microfiltration membranes prepared by phase inversion process. J Colloid Interface Sci 1991; 147(2): 307-315.

http://dx.doi.org/10.1016/0021-9797(91)90162-2 
[23] Fan H, Peng Y, Li Z, Chen P, Jiang Q, Wang S. Preparation and characterization of hydrophobic PVDF membranes by vapor-induced phase separation and application in vacuum membrane distillation. J Polym Res 2013; 20(6): 1-15. http://dx.doi.org/10.1007/s10965-013-0134-4

[24] Thomas R, Guillen-Burrieza E, Arafat HA. Pore structure control of PVDF membranes using a 2-stage coagulation bath phase inversion process for application in membrane distillation (MD). J Membr Sci 2014; 452: 470-480. http://dx.doi.org/10.1016/j.memsci.2013.11.036

[25] Mulder M. Basic principles of membrane technology. Dordrecht [u.a.: Kluwer 1996.

[26] Schofield RW, Hogan PA, Fane AG, Fell CDJ. Developments in membrane distillation. Desalination 1987; 62: 728.

[27] Guillen-Burrieza E, Thomas R, Mansoor B, Johnson D, Hilal $\mathrm{N}$, Arafat $\mathrm{H}$. Effect of dry-out on the fouling of PVDF and
PTFE membranes under conditions simulating intermittent seawater membrane distillation (SWMD). J Membr Sci 2013; 438: $126-139$

http://dx.doi.org/10.1016/j.memsci.2013.03.014

[28] Saffarini RB, Summers EK, Arafat HA. Technical evaluation of stand-alone solar powered membrane distillation systems. Desalination 2012; 286: 332-341.

http://dx.doi.org/10.1016/j.desal.2011.11.044

[29] Essalhi M, Khayet M. Surface segregation of fluorinated modifying macromolecule for hydrophobic/hydrophilic membrane preparation and application in air gap and direct contact membrane distillation. J Membr Sci 2012; 417: 163173.

http://dx.doi.org/10.1016/j.memsci.2012.06.028 